УДК 537.876.23; 550.837.62

\title{
ИССЛЕДОВАНИЕ ТРЕЩИНОВАТОСТИ НА МЕСТОРОЖДЕНИИ ОБЛИЦОВОЧНОГО КАМНЯ С ПРИВЛЕЧЕНИЕМ МЕТОДА ГЕОРАДИОЛОКАЦИИ
}

\author{
Данильев Сергей Михайлович1, \\ Danilev_SM@pers.spmi.ru, daniliev@mail.ru
}

\author{
Данильева Наталья Андреевна ${ }^{1}$, \\ Danileva_NA@pers.spmi.ru
}

Исакова Екатерина Павловна ${ }^{1}$, isakowa.ek@yandex.ru

\author{
Ашкар Георгий Хабибович², \\ georgiyashkar@gmail.com \\ 1 Санкт-Петербургский горный университет, \\ Россия, 199106, г. Санкт-Петербург, Васильевский остров, 21 линия, 2 \\ 2 Учебный центр Heriot-Watt программы Reservoir Evaluation and Management, \\ Россия, 634034, г. Томск, ул. Усова, 4а.
}

Актуальность исследования обусловлена необходимостью преждевременного определения не только поверхностного распределения трещин, но и степени внутреннего растрескивания горной породы при оценке трещиноватости основной породы применительно к месторождениям облицовочного камня. В современной практике при разработке месторождений облииовочного камня в большинстве случаев исследования трещиноватости ограничиваются лишь визуальным картированием, что не дает возможности получить представление о внутреннем пространственном распределении трещин, которые, в свою очередь, будут определять направление разрушения породы при отработке массива скальных пород. От правильного и рационального решения этой задачи зависит дальнейшая разработка месторождений облицовочного или строительного камня. Решение задачи локализации пространственного распределения трещин может базироваться на привлечении современных технологий, прочно внедрившихся в практику инженерной геофизики и позволяющих без десоормирования и вмешательства в поверхность проводить исследования пространственной ориентировки трещин в массиве породы. Аналитические исследования и экспериментальные наблюдения в естественных условиях обеспечивают возможность предварительно диффференцировать исследуемую территорию по степени трещиноватости массива горной породы, а также произвести качественную оценку блочного сырья.

Цель: выбор оптимального комплекса геофизических методов, обеспечивающих изучение распространения и локализации трещиноватости в массиве горных пород.

Методы: георадиолокационные исследования с применением прибора ОКО-2 с антеннами 150 и 1200 МГи.

Результаты. На основе проведенного изыскания предложено использование двух типов антенн с целью проникновения на различные глубины. Получена общая характеристика месторождения блочного камня, произведено выделение исследуемой площади по степени трещиноватости. Представленные методы отображают эфффективность исследования трещиноватости на месторождении облицовочного камня методом георадиолокации.

\section{Ключевые слова:}

Гранитный массив, трещиноватость, георадиолокационные исследования скальных пород, георадар, трещиноватость облицовочного камня.

\section{Введение}

При оценке трещиноватости основной породы крайне важно преждевременно определить не только поверхностное распределение трещин, но и степень внутреннего растрескивания горной породы. В связи с этим изучение трещиноватости на месторождениях облицовочного камня является одной из основных, тяжелых и требующих детальных исследований задач [1-3].

От правильного и целесообразного решения этой задачи зависит последующая разработка месторождений облицовочного или строительного камня. В имеющихся условиях проводится вспомогательные геофизические исследования зон трещиноватости горного массива при поиске и разведке месторождений облицовочного камня [4]. Геофизические методы могут быть успешно применены в качестве одного из способов улучшения эффективности геологоразведочных исследований на месторождениях данного типа $[5,6]$. Причина кроется в том, что тектонические нарушения горного массива имеют высококонтрастное отображения в геофизических полях $[7,8]$.

В частности, имеется опыт электрофотографических и георадиолокационных работ на месторождениях облицовочного камня, являющихся эффективными методами при изучении рассматриваемой проблемы [9, 10 и др.].

Оба метода успешно проявили себя при исследовании верхней части геологической среды, обладают надлежащей точностью при обнаружении маломощных неоднородностей, способны разрешить обширный диапазон задач, характерными особенностями данных методов являются высокая продуктивность и сравнительно низкая стоимость [10, 11 и др.]. 


\section{Исследование гранитных массивов}

Наиболее значимой структурной чертой массива скальных горных пород является присутствие большого числа поверхностей ослаблений или различных неоднородностей от контактов между единичными минеральными зёрнами, микро- и макротрещиноватости до региональных и планетарных разрывных структур - разломов. Мера распределения неоднородностей разнообразна, тем не менее применительно к скальным массивам весьма характерна высокая ориентированность в пространстве. По М.В. Рацу имеется классификация основных типов неоднородностей (таблица) [12, 13 и др.].

Таблица. Классификация основных типов неоднородностей

Table. Classification of common heterogeneities types

\begin{tabular}{|c|c|c|}
\hline Структура/Structure & $\begin{array}{l}\text { Порядок структуры } \\
\text { Structure order }\end{array}$ & $\begin{array}{l}\text { Мощность, м } \\
\text { Thickness, } \mathrm{m}\end{array}$ \\
\hline $\begin{array}{l}\text { Региональные неоднородности земной коры } \\
\text { Regional inhomogeneities of the Earth's Crust }\end{array}$ & ( & $\begin{array}{c}\text { Свыше } 10 \text { км } \\
\text { Over } 10 \mathrm{~km}\end{array}$ \\
\hline $\begin{array}{l}\text { Глубинные, сейсмогенные нарушения, разломы } \\
\text { Deep, seismogenic disturbances, faults }\end{array}$ & I & $\begin{array}{l}\text { Десятки и сотни метров } \\
\text { Tens and hundreds of meters }\end{array}$ \\
\hline $\begin{array}{l}\text { Неоднородности в пределах одной пачки, слоя пород, } \\
\text { естественная трещиноватость } \\
\text { Inhomogeneities within a single member, rock layer, natural fracture }\end{array}$ & II & $\begin{array}{l}\text { Единицы и первые десятки метров } \\
\text { Units and first tens of meters }\end{array}$ \\
\hline $\begin{array}{l}\text { Микротрещинноватость, контакты между отдельными } \\
\text { образованиями, зёрнами кристаллами } \\
\text { Microcracking, contacts between separate formations, grains, crystals }\end{array}$ & III & $\begin{array}{l}\text { Единицы до десятков сантиметров } \\
\text { Units up to tens of centimeters }\end{array}$ \\
\hline \multirow[t]{2}{*}{$\begin{array}{l}\text { Нарушения межкристаллических областей } \\
\text { Intercrystalline disturbances }\end{array}$} & IV & $\begin{array}{c}\text { Доли миллиметра до нескольких } \\
\text { сантиметров } \\
\text { Fractions of a millimeter to a few } \\
\text { centimeters }\end{array}$ \\
\hline & $\mathrm{V}$ & $\begin{array}{l}\text { До долей миллиметров } \\
\text { To fractions of millimeters }\end{array}$ \\
\hline
\end{tabular}

Применительно к месторождениям блочного камня действенным типом структурных неоднородностей можно назвать неоднородности III порядка.

Все геофизические методы базируются на корреляции параметров состояния и свойств массива горных пород с параметрами разного рода физических полей $[14,15]$. Однако геофизические методы госконтроля неявны или условны, так как при интерпретации необходимо брать в расчет массивный набор действующих факторов, для дифференцирования которых применяются методы относительно контроля во времени или относительно эталонного участка массива [16-19].

По производительности и информативности оценки неоднородности массива пород из геофизических методов выделяются георадиолокационный метод с частотным диапазоном до 1200 Гц.

Трещины III порядка относительно степени раскрытия и «компонента наполнения» могут быть «открытыми», т. е. сплошными для упругой волны определенной частоты, или «закрытыми» $[20,21]$. Открытые трещины искажают геометрию проходящих лучей, закрытые трещины привносят свои поправки лишь в снижение интегральных упругих модулей и действительных скоростей упругих волн. Если в трещинах наблюдается отсутствие свободной воды, то такая обусловленность дает возможность с некоторой долей достоверности дать оценку трещиноватости III порядка по скоростям продольных волн [22].

В качестве иллюстрации возможностей ранжирования массива пород по трещиноватости и соответственно выходу кондиционных блоков приведена технология георадиолокационного исследования на Юго-Востоке Республики Карелия. Участок недр примыкает с востока к разведанной части месторождения гранитов.
Измерения поводились по пяти профилям с дневной поверхности в режиме непрерывной записи георадара. Мощность пород исследуемой толщи составляет 22-30 м. Длина измеряемого профиля по поверхности составила 50 м. Расстояние между профилями составляло $10 \mathrm{~m}$.

Георадарное зондирование выполнено на участках с целью прослеживания субгоризонтальной трещиноватости, т. к. в процессе отработки месторождения зафиксированы субгоризонтальные зоны трещиноватости.

Георадарные исследования проводились с помощью георадара «ОКО-2» с антеннами 150 и 1200 МГц. Частота полезного сигнала составила 100-250 МГц. Для получения приемлемого полезного сигнала применялось накопление до 20 раз.

Два типа антенн использовались с целью проникновения на несколько десятков

метров для обнаружения субгоризонтальных трещин, георадар с меньшой частотой - для оконтуривания зоны четвертичный отложений.

Обработка георадиолокационных данных выполнена с помощью специализированной программы «Prism 2.5». Георадиолокационная обработка состояла из двух этапов: решение прямой и обратной задач. Решение обратной задачи проводилось методом фильтрации и преобразованием Гильберта.

Опытное георадарное зондирование проведено на частично вскрытой части месторождения (рис. 1). Изза неравномерной мощности четвертичных отложений (0,3-3 м) и приповерхностных неоднородности коренных пород (трещиноватости, наличие ксенолитов основных пород) предельная глубина зондирования составила около 30 м. По документации в процессе отработки месторождения зафиксированы субгоризонтальные зоны трещиноватости на 12-13 м, 
развитые в массиве гранитоидов. На разрезе наблюдается корреляция с результатами отбора керна в скважине. Наиболее «чистые» участки радарограммы отвечают монолитам.

С использованием программного обеспечения пакета Voxler удалось отобразить наличие трещиноватости горного массива на установленных глубинах, а также визуализировать полученные данные. Благода- ря построению объемной модели можно проследить распространение трещины по участку.

Рис. 2 показывает распространение трещины по изучаемому участку. Отмечается ярко выраженная трещиноватость, соответствующая глубинам 12-13 м. Следовательно, данный интервал глубин представляет повышенную заинтересованность для изучения месторождения облицовочного камня.

$\mathrm{C}$

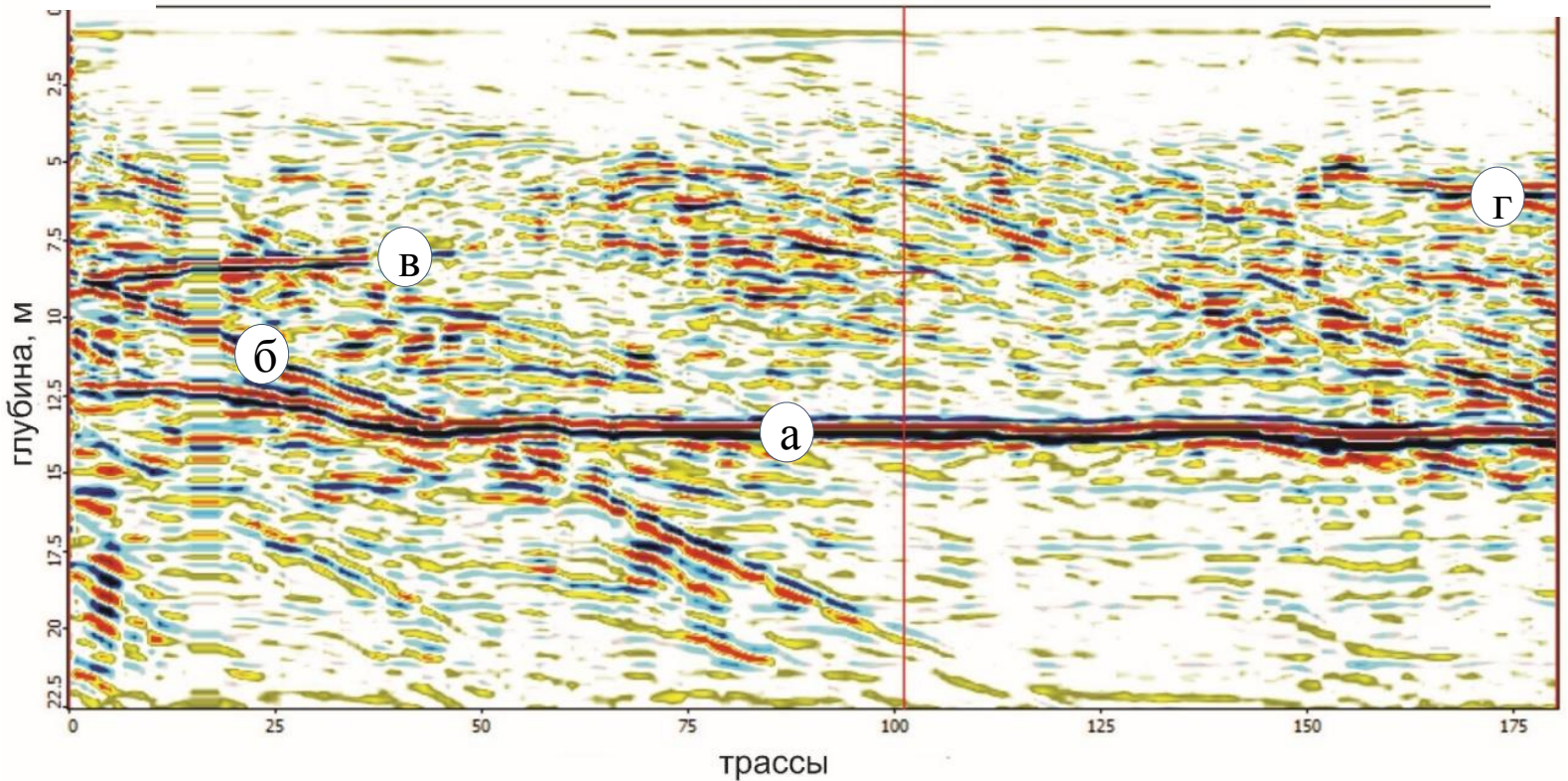

Pис. 1. Георадиолокаиионный разрез исследуемого массива пород

Fig. 1. Georadiolocational cross section of studied rock mass

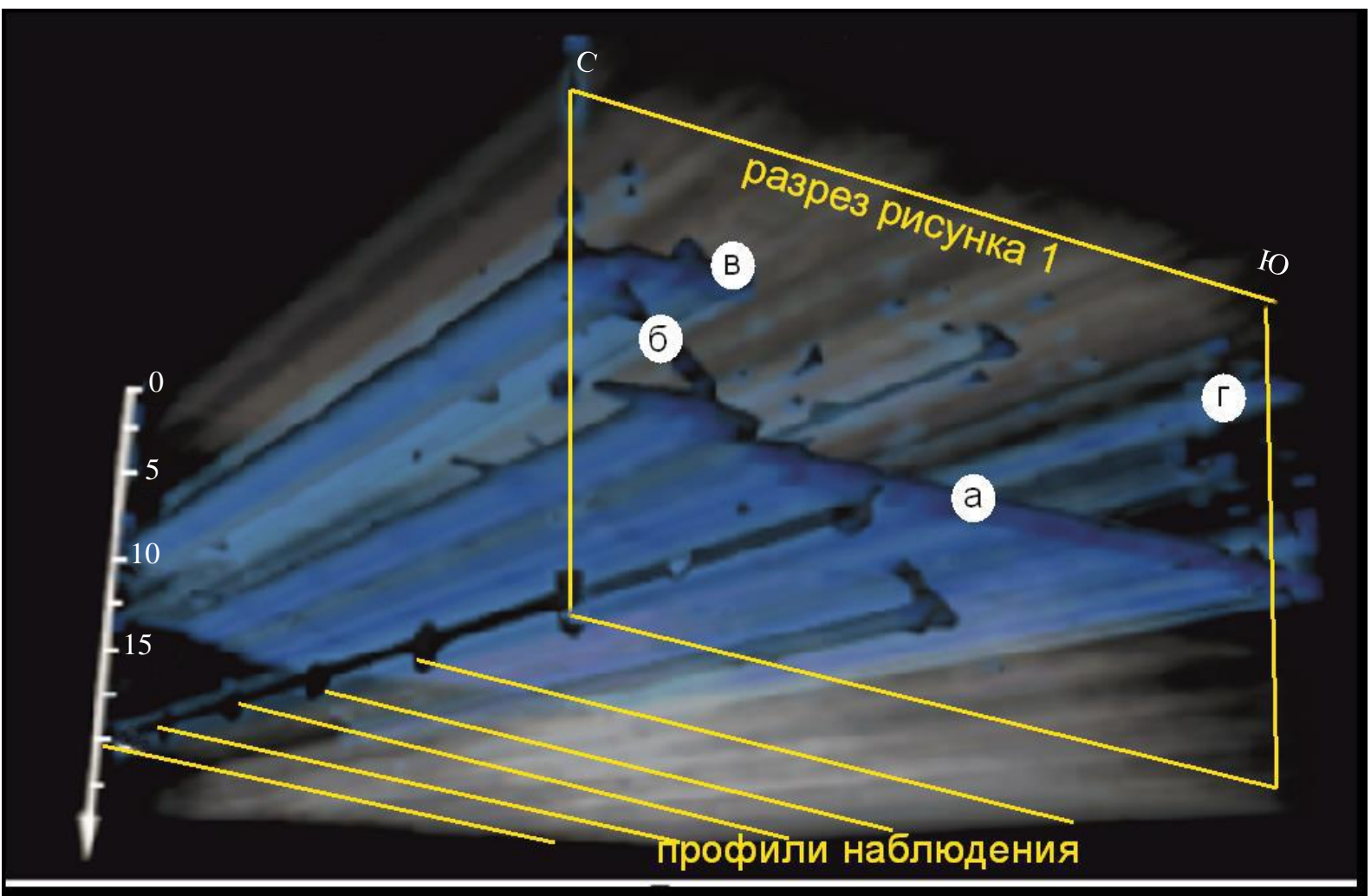

Pис. 2. Объемная модель трещиноватости

Fig. 2. 3-D model of cracking 


\section{Заключение}

На основе исследования свойств трещиноватости горного массива и практических наблюдений в естественных условиях можно отметить, что георадарная съемка является одной из перспективных методик при поиске и разведки месторождений блочного камня. Несмотря на то, что эффективная глубина исследований составила около 25 м, данные бурения и гео-

\section{СПИСОК ЛИТЕРАТУРЫ}

1. Данильев С.М., Данильева Н.А. Перспективы электроразведочных исследований дамб гипсонакопителей в рамках геотехнического мониторинга // Инженерная и рудная геофизика 2019: 15-я юбилейная научно-практическая конференция и выставка. Тезисы доклада. - Геленджик, 2019. - С. 278-284.

2. Данильев С.М., Данильева Н.А. Особенности электромагнитного поля георадарограмм при исследовании скрытых полостей в инженерно-технических объектах // Инженерная и рудная геофизика 2018: 14-я научно-практическая конференция и выставка. - Алматы, Казахстан, 2018. - С. 256-260.

3. Комплексирование методов тепловизионного и георадиолокационного сканирования для выявления полостей под железобетонными плитами крепления грунтовых откосов гидротехнических сооружений / С.М. Данильев, В.В. Глазунов, Н.Н. Ефимова, В.С. Недялков, В.Г. Штенгель // Инженерная и рудная геофизика 2018: 14-я научно-практическая конференция и выставка. - Алматы, Казахстан, 2018. - С. 318-324.

4. Данильев С.М., Данильева Н.А. Частотные составляющие динамических атрибутов волнового электромагнитного поля георадарограмм // International Journal of Engineering \& Technology (2.13). - 2018. - № 7. - C. 127-132.

5. Жиров Д.В., Мелихова С.Г., Рыбин В.В. Особенности инженерно-геологического изучения массивов скальных пород в целях проектирования глубоких карьеров на примере Ковдорского месторождения магнетитовых и апатитовых руд // Вестник Кольского научного центра РАН. - 2016. - № 2 - С. 19-29.

6. Трещиноватость породного массива в карьере рудника «Железный» АО «Ковдорский ГОК» / И.М. Игнатенко, Е.Б. Яницкий, В.А. Дунаев, С.Г. Кабелко // Горный журнал. - 2019. № 10. - С. 11-14.

7. Латышев О.Г. Неоднородность трещинной структуры и прочность горных пород // Известия вузов. Горный журнал. 2014. - № 6. - С. 152-159.

8. Латышев О.Г., Прищепа Д.В. Прогноз деформационных характеристик трещиноватого породного массива // Известия вузов. Горный журнал. - 2017. - № 1. - С. 80-85.

9. Красновский А.А. О деформировании блоков пород с полостью // Фундаментальные и прикладные вопросы горных наук. - 2017. - Т. 4. - № 2. - С. 76-79.

10. Ольховатенко В.Е., Трофимова Г.И., Ожогина Т.В. Методы изучения трещиноватости горных пород. - Томск: Изд-во Том. гос. архит.-строит. ун-та, 2015. - 80 с. радарограммы полностью коррелируют друг друга. На полученных данных тенденция волнового поля резко отличается, при этом наблюдается явное прослеживание субгоризонтальных нарушений. На основе проведенных исследований можно судить о необходимости методически доказанного применения георадара для исследования трещиноватости, а также более детального исследования данной проблемы.

11. Рязанцев П.А. Повышение эффективности разведки месторождений облицовочного камня на основе электротомографии: дис. ... канд. геол.-минерал. наук. - СПб, 2015. - 169 с.

12. Рац М.В., Чернышев С.Н. Трещиноватость и свойства трещиноватых горных пород. - М.: Недра, 1970. - 164 с.

13. Облицовочный камень Ленинградской области. Граниты Карельского перешейка в современной архитектуре СанктПетербурга / А.Я. Тутакова, А.3. Романовский, А.Г. Булах, Ю.В. Лир. - СПб.: Русская коллекция, 2011. - 80 с.

14. Ashmole I., Motloung M. Dimension stone: the latest trends in exploration and production technology // Surface Mining. 2008. - P. 35-70.

15. Bedrock detection beneath river terrace deposits using threedimensional electrical resistivity tomography / J. Chambers, P. Wilkinson, D. Wardrop, A. Hameed, I. Hill, C. Jeffrey, M.H. Loke, P.I. Meldrum, O. Kuras, M. Cave, D.A. Gunn // Geomorphology. - 2012. - V. 177. - P. 17-25

16. Clifford J., Binley A. Geophysical characterization of riverbed hydrostratigraphy using electrical resistance tomography // Near Surface Geophysics. - 2010. - V. 8. - P. 563-574.

17. Elmouttie M.K., Poropat G.V. A method to estimate in situ block size distribution // Rock Mechanics and Rock Engineering. 2012. - V. 45. - P. 401-407.

18. National treasure of global significance. Dimension-stone deposits in larvikite, Oslo igneous province, Norway / T. Heldal, I. Kjolle, G.B. Meyer, S. Dahlgren // Geological Survey of Norway Special Publication. - 2008. - V. 11. - P. 5-18.

19. Mufti I.R. Finite-difference resistivity modeling for arbitrarily shaped two-dimensional structure // Geophysics. - 1976. V. 41. - P. 62-78.

20. Case study: a 3D resistivity and induced polarization imaging from downstream a waste deposal site in Brazil / A. Ustra, V. Elis, G. Mondelli, L. Zuquette, H. Giacheti // Environment Earth Science. - 2012. - V. 66. - P. 763-772.

21. Practical aspects of applied optimized survey design for electrical resistivity tomography / P.B. Wilkinson, M.H. Loke, P.I. Meldrum, J.E. Chambers, O. Kuras, D.A. Gunn, R.D. Ogilvy // Geophysical Journal International. - 2012. - V. 189. - P. 428-440.

22. Zhamaletdinov A.A., Ronning J.S., Vinogradov Y.A. Electrical profiling by the MISC and Slingram methods in the PechengaPasvik area. Norges Geologiske Undersokelse, Special publication. -1995 . - V. 7. - P. 333-338.

Поступила: 20.02.2020 г.

\section{Информация об авторах}

Данильев С.М., кандидат геолого-минералогических наук, доцент кафедры геофизических и геохимических методов поиска и разведки месторождений полезных ископаемых Санкт-Петербургского горного университета.

Данильева Н.А., кандидат геолого-минералогических наук, доцент кафедры геофизических и геохимических методов поиска и разведки месторождений полезных ископаемых Санкт-Петербургского горного университета.

Исакова E.П., студентка геологоразведочного факультета, кафедры геофизических и геохимических методов поиска и разведки месторождений полезных ископаемых Санкт-Петербуржского горного университета.

Аикар Г.X., слушатель учебного центра Heriot-Watt программы Reservoir Evaluation and Management. 
UDC 537.876.23; 550.837 .62

\title{
RESEARCH OF CRACKING AT FACING STONE DEPOSIT USING THE GEORADAR METHOD
}

\author{
Sergey M. Daniliev 1 , \\ Danilev_SM@pers.spmi.ru, daniliev@mail.ru
}

Natalya A. Danilieva', Danileva_NA@pers.spmi.ru

Ekaterina P. Isakova1, isakowa.ek@yandex.ru

\author{
George K. Ashkar², \\ georgiyashkar@gmail.com \\ 1 St. Petersburg Mining University, \\ 2, 21 line Vasilievsky Island, St. Petersburg, 199106, Russia. \\ 2 Heriot-Watt Reservoir Evaluation and Management Training Center, \\ 4a, Usov street, Tomsk, 634034, Russia.
}

\begin{abstract}
The relevance of the study is specified by the necessity not only to identify the surface distribution of cracks, but also the degree of vegetation of the rock when evaluating the fracture of the main rocks as applied to the facing stone deposits. In modern practice, when developing deposits, the rock with various types of distributed cracks can be detected. The further development of deposits of facing or building stone depends on the correct and rational solution to this problem. The solution to the problems of localization of the distributed propagation of cracks can be based on the attraction of modern technologies and introduction of engineering geophysicists into practice, allowing research based on the study of spatially oriented cracks in the rock mass. Analytical studies and experimental observations in natural conditions make it possible to preliminarily differentiate area of study by degree of demolition geological material mass, as well as to make a qualitative assessment of block raw materials.
\end{abstract}

The main aim of the research is to select the optimal complex of geophysical methods for studing the propagation and localization of fractures in a rock mass.

Methods: GPR studies using OKO-2 equipment with $150 \mathrm{MHz}$ and $1200 \mathrm{MHz}$ antennas.

Results. Based on the study, the authors have proposed to use two types of antennas for penetrating to different depths. The general characteristic of the block stone deposit is obtained, the study area is allocated according to the degree of fracture. The presented methods reflect the effectiveness of the study of fracturing in a facing stone deposit using georadar.

\section{Key words:}

Granite massif, fracturing, GPR studies of rock, GPR, fracturing of a facing stone.

\section{REFERENCES}

1. Daniliev S.M., Danilieva N.A. Prospects for electrical exploration studies of gypsum storage dams in the framework of geotechnical monitoring. 15th anniversary scientific-practical conference and exhibition "Engineering and ore geophysics 2019". Gelendzhik, EAGE, 2019. pp. 278-284.

2. Daniliev S.M., Daniliev N.A. Osobennosti elektromagnitnogo polya georadarogramm pri issledovanii skrytykh polostey [Features of the electromagnetic field of GPR in the study of hidden cavities in engineering facilities]. 14ya nauchnoprakticheskaya konferentsya $i$ vystavka. Inzhenernaya i rudnaya geofizika $2018\left[14^{\text {th }}\right.$ Scientific and Practical Conference and Exhibition. Engineering and Ore Geophysics 2018]. Almaty, Kazakhstan, EAGE, 2018. pp. 256-260.

3. Daniliev S.M., Glazunov V.V., Efimova N.N., Nedyalkov V.S Stengel V.G. Kompleksirovanie metodov teplovizionnogo i georadiolokatsyonnogo skanirovaniya dlya vyyavleniya polostey pod zhelezobetonnymi plitami krepleniya gruntovykh otkosov gidrotehnicsheskikh sooruzheniy [Combining the methods of thermal imaging and GPR scanning for revealing cavities under reinforced concrete slabs for attaching soil slopes of hydraulic structures]. 14ya nauchno-prakticheskaya konferentsya i vystavka. Inzhenernaya $i$ rudnaya geofizika $2018\left[14^{\text {th }}\right.$ Scientific and Practical Conference and Exhibition. Engineering and Ore Geophysics 2018]. Almaty, Kazakhstan, EAGE, 2018. pp 318-324.

4. Daniliev S.M., Daniliev N.A. Frequency components of dynamic attributes of a wave electromagnetic field of georadarograms. International Journal of Engineering \& Technology (2.13), 2018 , no. 7, pp. 127-132. In Rus.
5. Zhirov D.V., Melikhova S.G., Rybin V.V. Peculiarities of engineering-geological study of rock massifs for the design of deep quarries using the example of the Kovdor deposit of magnetite and apatite ores. Bulletin of the Kola Science Center of the Russian Academy of Sciences, 2016, vol. 2, pp. 15-25. In Rus.

6. Ignatenko I.M., Yanitsky E.B., Dunaev V.A., Kabelko S.G. Fracturing of the rock mass in the quarry of the Zhelezny mine of Kovdorsky GOK JSC. Mining Journal, 2019, no. 10, pp. 11-14. In Rus.

7. Latyshev O.G. Heterogeneity of the fracture structure and rock strength. Bulletin of universities. Mountain Journal, 2014, no. 6, pp. 152-159. In Rus.

8. Latyshev O.G., Prishchepa D.V. Forecast of the deformation characteristics of a fractured rock mass. Proceedings of universities. Mountain Journal, 2017, no. 1, pp. 80-85. In Rus.

9. Krasnovsky A.A. On the deformation of rock blocks with a cavity. Fundamental and Applied Questions of Mining Sciences, 2017, vol. 4, no. 2. pp. 76-79. In Rus.

10. Olkhovatenko V.E., Trofimova G.I., Ozhogina T.V. Metody izucheniya treshchinovatosti gornykh porod [Methods of studying rock fracturing]. Tomsk, Tomsk State Architect Build University Publ. house, 2015. $80 \mathrm{p}$.

11. Ryazantsev P.A. Povyshenie effektivnosti razvedki mestorozhdeniy oblitsovochnogo kamnya na osnove elektrotomografii. Avtoreferat Dis. Kand. nauk [Increasing the efficiency of exploration of facing stone deposits based on electrotomography. Cand. Diss. Abstract]. Saint-Petersburg, 2015. 169 p.

12. Rat M.V., Chernyshev S.N. Trecshinovatost $i$ svoystva treshchinovatykh gornykh porod [Fracturing and properties of fractured rocks]. Moscow, Nedra Publ, 1970. 164 p. 
13. Tutakova A.Ya., Romanovsky A.Z., Bulakh A.G., Lir Yu.V. Oblitsovochny kamen Leningradskoy oblasti. Granity Karelskogo peresheyka $v$ sovremennoy arhitekture Sankt-Peterburga [Facing stone of the Leningrad region. Granites of the Karelian Isthmus in the modern architecture of St. Petersburg]. St. Petersburg, Russkaya kollektsiya Publ., 2011. 80 p.

14. Ashmole I., M Motloung. Dimension stone: the latest trends in exploration and production technology. Surface Mining, 2008, pp. $35-70$.

15. Chambers J., Wilkinson P., D. Wardrop, Hameed A., Hill I., Jeffrey C., Loke M.H., Meldrum P.I., Kuras O., Cave M. Gunn D.A. Bedrock detection beneath river terrace deposits using three-dimensional electrical resistivity tomography. Geomorphology, 2012, vol. 177, pp. 17-25.

16. Clifford J., Binley A. Geophysical characterization of riverbed hydrostratigraphy using electrical resistance tomography. Near Surface Geophysics, 2010, vol. 8, pp. 563-574.

17. Elmouttie M.K., Poropat G.V. A method to estimate in situ block size distribution. Rock Mechanics and Rock Engineering, 2012, vol. 45, pp. 401-407.
18. Heldal T., Kjolle I., Meyer G.B., Dahlgren S. National treasure of global significance. Dimension-stone deposits in larvikite, Oslo igneous province, Norway. Geological Survey of Norway Special Publication, 2008, vol. 11, pp. 5-18.

19. Mufti I.R. Finite-difference resistivity modeling for arbitrarily shaped two-dimensional structure. Geophysics, 1976, vol. 41, pp. $62-78$.

20. Ustra A., Elis V., Mondelli G., Zuquette L., Giacheti H. Case study: a 3D resistivity and induced polarization imaging from downstream a waste deposal site in Brazil. Environment Earth Science, 2012, vol. 66, pp. 763-772.

21. Wilkinson P.B., Loke M.H., Meldrum P.I., Chambers J.E., Kuras O., Gunn D.A., Ogilvy R.D. Practical aspects of applied optimized survey design for electrical resistivity tomography. Geophysical Journal International, 2012, vol. 189, pp. 428-440.

22. Zhamaletdinov A.A., Ronning J.S., Vinogradov Y.A. Electrical profiling by the MISC and Slingram methods in the PechengaPasvik area. Norges Geologiske Undersokelse, Special publication, 1995, vol. 7. pp. 333-338.

Received: 20 February 2020.

\section{Information about the authors}

Sergey M. Daniliev, Cand. Sc., associate professor, St. Petersburg Mining University.

Natalya A. Danilieva, Cand. Sc., associate professor, St. Petersburg Mining University.

Ekaterina P. Isakova, student, St. Petersburg Mining University.

George K. Ashkar, student, Heriot-Watt Reservoir Evaluation and Management Training Center. 